\title{
Diversidade fenotípica e patogênica de Colletotrichum, agente causal da antracnose em mangueira, e identificação de espécie
}

\author{
Ilka Márcia Ribeiro de Souza Serra ${ }^{1}$, Rildo Sartori Barbosa Coelho², Gabriela de Moraes Guerra Ferraz ${ }^{3}$, Angélica \\ Virgínia Valois Montarroyos ${ }^{3}$ e Denise de Santos Silva ${ }^{2}$
}

${ }^{1}$ Departamento de Fitotecnia e Fitossanidade, Universidade Estadual do Maranhão, CP 2002, 65041-970; ${ }^{2}$ Departamento de Agronomia e Fitossanidade, Universidade Federal Rural de Pernambuco, Dois Irmãos, CEP: 52171-900, Recife, PE; ${ }^{3}$ Departamento de Ciências Biológicas, Universidade Federal de Pernambuco.

Autor para correspondência: Ilka Márcia R. de S. Serra. (ilka.tt@gmail.com)

Data de chegada: 31/10/2008. Aceito para publicação em: 26/01/2011.

\section{RESUMO}

Serra, I.M.R.S.; Coelho, R.S.B.; Ferraz, G.M.G.; Montarroyos, A.V.V. \& Silva, D.S. Diversidade fenotípica e patogênica de Colletotrichum, agente causal de antracnose em mangueira, e identificação de espécie. Summa Phytopathologica, v.37, n.1, p.42-51, 2011.

O presente trabalho teve como objetivo estudar a diversidade fenotípica e patogênica de 40 isolados de Colletotrichum obtidos de mangueira no Nordeste do Brasil e identificar diferentes espécies desse fitopatógeno, agente causal de antracnose, através da análise da seqüência da região ITS do rDNA. Quanto à caracterização morfológica e cultural, as colônias dos isolados apresentaram diversidade em relação à cor e aspecto, sendo mais comum à cor branco-cinza, característica de Colletotrichum gloeosporioides. Não foram observadas variações expressivas na morfologia dos 40 isolados. Os conídios apresentaram-se, predominantemente, hialinos e unicelulares, com formato variando de bastonete para cilíndrico. Todos os isolados produziram apressórios variados em formato e quantidade e apenas 10 isolados apresentaram setas. Para efeito do crescimento micelial e taxa de crescimento foi possível classificar os isolados em sete grupos. Vinte e dois isolados exibiram taxa de crescimento $>10 \mathrm{~mm} / \mathrm{dia}$, considerada típica da espécie C. gloeosporioides. Os isolados foram patogênicos em folhas destacadas de mangueira, induzindo sintomas de antracnose, na forma de manchas escuras levemente deprimidas, e apresentando variações quanto à agressividade. Na identificação específica, baseada na análise da seqüência ITS do DNA ribossomal, 36 isolados amplificaram com o oligonucleotídeos CgInt, específico para C. gloeosporioides e o ITS4, Os isolados CM1, CM4, CM5 e CM10, não amplificaram produtos para nenhum dos oligonucleotídeos específicos, sendo identificados como Colletotrichum spp. Os resultados desse trabalho demonstraram que isolados de Colletotrichum, obtidos de mangueira, apresentam ampla variabilidade morfofisiológica e patogênica. E que, possivelmente, existe mais de uma espécie de Colletotrichum que causa antracnose em mangueira no Nordeste do Brasil.

Palavras-chave adicionais: Mangifera indica, patogenicidade, rDNA, Glomerella cingulata

\section{ABSTRACT}

Serra, I.M.R.S.; Coelho, R.S.B.; Ferraz, G.M.G.; Montarroyos, A.V.V. \& Silva, D.S.. Phenotypic and pathogenic diversity in Colletotrichum, causal agent of anthracnose in mango and identification of species. Summa Phytopathologica, v.37, n.1, p.42-51, 2011.

The present work aimed to study the phenotypic and pathogenic diversity of 40 Colletotrichum isolates obtained from mango trees in the Northeast of Brazil and to identify different species of this pathogen, incitant of anthracnose, through the analysis of the ITS sequence of the ribosomal DNA. As for the morphologic and cultural characterization, the colonies of the isolates presented diversity in relation to color and aspect, being more common the color white-ash, characteristic of C. gloeosporioides. Expressive variations were not observed in the morphology of the 40 isolates. The conidia were predominantly hyaline and unicellular varying in shape from rod to cylindrical. All isolates produced appressoria of different shapes and in different amounts, and 10 isolates showed setae. In relation to mycelial growth and growth rate the isolates were classified in seven groups. Twenty-two isolates exhibited growth rate $>10 \mathrm{~mm} /$ day, considered typical of $C$. gloeosporioides species. The isolates were pathogenic to detached leaves of mango, inducing anthracnose symptoms such as dark lesions slightly depressed, and presenting variations of aggressiveness. In the specific identification based on the analysis of the ITS sequence of the ribosomal DNA, 36 isolates amplified with the primer CgInt, specific for C. gloeosporioides and with the primer ITS4. Isolates CM1, CM4, CM5 and CM10 did not amplify products for none of the specific primers, being identified as Colletotrichum spp. The results of this work demonstrate that Colletotrichum isolates obtained from mango trees present large morphophysiologic and pathogenic variability, and also that, possibly exists more than one species of Colletotrichum that causes anthracnose in mango trees in the Northeast of Brazil.

Palavras-chave adicionais: Mangifera indica, pathogenicity, rDNA, Glomerella cingulata 
A antracnose, causada por espécies do gênero Colletotrichum, é uma das doenças mais comuns e importantes em frutíferas, apresentando ampla distribuição geográfica e ocasionando problemas em regiões tropicais, subtropicais e temperadas. Ocorre tanto nas fases de desenvolvimento vegetativo, como reprodutiva de diversos hospedeiros, sendo mais severa quando afeta os frutos (13).

No Brasil, a antracnose está disseminada em todas as regiões de cultivo da mangueira (Mangifera indica $\mathrm{L}$.), constituindo fator limitante na exportação de frutos (9). O patógeno ataca folhas, ramos, inflorescências, pedúnculos e frutos, ocasionando prejuízos que variam em função do grau de suscetibilidade da planta hospedeira e das condições ambientais, sendo mais acentuados em épocas úmidas com temperaturas amenas (27). No Nordeste, a mangueira é cultivada em todos os estados, em particular nos perímetros irrigados da região semi-árida, que apresentam excelentes condições para o desenvolvimento da cultura e obtenção de elevada produtividade e qualidade dos frutos. Nessa região, as principais áreas cultivadas de manga estão localizadas na Bahia, Pernambuco e Ceará. Nesses Estados, a antracnose é a doença mais importante da mangueira, por força da elevada incidência e severidade, principalmente em frutos durante o desenvolvimento e na pós-colheita.

$\mathrm{O}$ agente causal de antracnose em mangueira e outras fruteiras tropicais no Brasil como abacate, acerola, goiaba, caju, mamão, maracujá, citrus e outras, tem sido referido como Colletotrichum gloeosporioides (Penz.) Penz. \& Sacc. (22). Relatos sobre doenças causadas por C. gloeosporioides em diversos hospedeiros têm demonstrado freqüentemente que o fungo apresenta ampla variabilidade morfológica, fisiológica e patogênica $(2,3,28)$. O gênero Colletotrichum é notoriamente variável em relação a determinadas características, destacando-se a patogenicidade, demonstrada em diversos patossistemas como C. graminicola (Ces.) G.W.Wils. - sorgo (8); $C$. lindemuthianum (Sacc. \& Magn.) Scrib. - feijoeiro comum (5); $C$. acutatum J.H. Simm. e C. gloeosporioides - morangueiro (16). Portanto a ocorrência de populações de Colletotrichum ssp. com comportamento patogênico diferenciado pode determinar variações na expressão da doença, interferindo na adoção de estratégias de controle (13).

A identificação da espécie de Colletotrichum responsável por antracnose em frutíferas é fundamental para o desenvolvimento e implantação de métodos eficientes no controle da doença. Freeman (14) descreve que várias espécies de Colletotrichum podem afetar um mesmo hospedeiro, citando como exemplos à antracnose em abacateiro e mangueira, causadas por $C$. gloeosporioides e $C$. acutatum, e em morangueiro por $C$. gloeosporioides, $C$. fragariae Brooks e $C$. acutatum. Por outro lado, segundo este mesmo autor, uma única espécie de Colletotrichum pode infectar diferentes hospedeiros.

Tradicionalmente, a caracterização e determinação taxonômica de Colletotrichum spp. têm sido quase que exclusivamente feita por meio de características morfológicas, culturais e patogênicas, como morfologia de conídios, formação de apressórios, presença e ausência de setas, presença e ausência de teleomorfo, coloração de colônias, taxa de crescimento micelial, além da gama de hospedeiro $(14,29)$. Atualmente, técnicas biotecnológicas têm sido empregadas para auxiliar nos estudos taxonômicos de Colletotrichum spp. Estas incluem análises da sequiência de nucleotídeos da região espaçadora transcrita (ITS) do DNA ribossomal (rDNA), de genes da b-tubulina 2 ( $t u b 2$ ) e histona 4 (his4), glutamina sintase (GS), genes introns gliceraldeído-3-fosfato desidrogenase (GPDH), DNA mitocondrial (mtDNA) e a utilização de marcadores como RAPDs, RFLPs e AFLPs $(15,32)$.

A eficiência de métodos de controle mais utilizados para a antracnose da mangueira depende do conhecimento da variabilidade e caracterização a nível específico do agente causal. Neste sentido, o presente trabalho teve como objetivo estudar a diversidade fenotípica e patogênica de isolados de Colletotrichum obtidos de mangueiras no Nordeste do Brasil e identificar diferentes espécies desse fitopatógeno agente causal de antracnose em mangueira, mediante a análise da seqüência da região ITS do rDNA.

\section{MATERIAL E MÉTODOS}

\section{Culturas fúngicas e condições de crescimento}

Os isolados foram obtidos de lesões típicas de antracnose de folhas de mangueira, provenientes de várias regiões do Nordeste brasileiro, conforme mostra a Tabela 1.

Após as etapas rotineiras de limpeza e desinfestação do material, fragmentos da região de transição, entre a lesão e os tecidos sadios (23) foram transferidos para placas de Petri contendo meio de cultura batata-dextrose-ágar (BDA) e, em seguida, incubados a $25 \pm 2^{\circ} \mathrm{C}$, sob alternância luminosa ( $12 \mathrm{~h}$ de claro/ $12 \mathrm{~h}$ de escuro). Posteriormente, fragmentos do micélio de colônias características do gênero Colletotrichum, foram transferidos para tubos contendo BDA e incubados nas mesmas condições já citadas. Os isolados foram codificados e, as culturas puras preservadas em tubos de ensaio contendo BDA, sob refrigeração $\left(5^{\circ} \mathrm{C}\right)$.

\section{Morfologia e características culturais de Colletotrichum em BDA}

Para os estudos morfológicos, todos os isolados de Colletotrichum foram avaliados quanto ao aspecto da colônia, forma e dimensões de conídios, formação de apressórios e ausência e presença de setas, empregando-se a técnica de microcultura (23) para auxiliar as análises morfológicas. A incubação foi realizada em condições de laboratório $\left(25^{\circ} \mathrm{C}\right.$, aproximadamente), durante o período de três a sete dias, sob condição de alternância luminosa (12h claro/ $12 \mathrm{~h}$ escuro). Foram medidos cinqüenta conídios de cada isolado. As dimensões desses conídios foram determinadas em microscópio óptico com aumento de 400x, utilizando-se de uma ocular micrométrica, anotando-se o comprimento e a largura média, além da amplitude de variação. Foi também observado o formato predominante dos mesmos, obtendo-se no final uma avaliação da variabilidade morfológica dos conídios.

Observações quanto à produção de apressórios também foram avaliadas, por meio da técnica de microcultura, permitindo a visualização da forma, coloração e quantidade formada, sendo documentados por fotomicrografias. Com relação às características das colônias, culturas dos quarenta isolados foram preparadas em BDA e incubadas, durante sete dias, nas mesmas condições citadas anteriormente. Quatro repetições foram preparadas para cada isolado. A avaliação consistiu na observação do aspecto topográfico das colônias e coloração das mesmas

\section{Caracterização fisiológica e patogênica de Colletotrichum obtidos de mangueira \\ Crescimento micelial em BDA \\ Para o estudo das características fisiológicas, discos da cultura de cada isolado (5,0mm de diâmetro), oriundos de colônia jovem, foram transferidos para o centro de placa de Petri, contendo meio BDA, as quais foram incubadas a $25 \pm 2^{\circ} \mathrm{C}$, sob condição de alternância luminosa (12h claro/ $12 \mathrm{~h}$ escuro). Foi observado o crescimento do micélio,}


Tabela 1 - Origens geográficas e genótipos hospedeiros de mangueira dos 40 isolados de Colletotrichum coletados no Nordeste do Brasil, usados no estudo.

\begin{tabular}{|c|c|c|c|}
\hline Isolados & Origem Geográfica/ Município/Estado & Região & Genótipos Hospedeiros \\
\hline CM2 & Casa Forte-PE & Metropolitana Recife & Manga Espada \\
\hline CM4 & Veneza-MA & Sertão maranhense & Manga Rosa \\
\hline CM5 & Veneza-MA & Sertão maranhense & Manga Espada \\
\hline CM8 & Camaragibe-PE & Metropolitana Recife & Manga Rosa \\
\hline CM9 & Paulista-PE & Zona da Mata Norte & Manga Espada \\
\hline CM10 & Paulista-PE & Zona da Mata Norte & Manga Comum \\
\hline CM11 & Paulista-PE & Zona da Mata Norte & Manga Rosa \\
\hline CM19 & Ipojuca-PE & Zona da Mata Sul & Manga Espada \\
\hline $\mathrm{CM} 22$ & Ipojuca-PE & Zona da Mata Sul & Manguito \\
\hline CM23 & Ipojuca-PE & Zona da Mata Sul & Manga Comum \\
\hline $\mathrm{CM} 24$ & Ipojuca-PE & Zona da Mata Sul & Manga Jasmim \\
\hline $\mathrm{CM} 26$ & Camaragibe-PE & Metropolitana Recife & Manga Maranhão \\
\hline $\mathrm{CM} 27$ & Cabo Sto. Agostinho-PE & Zona da Mata Sul & Manga Comum \\
\hline CM29 & Cabo Sto. Agostinho-PE & Zona da Mata Sul & Manga Espada \\
\hline CM30 & Cabo Sto. Agostinho-PE & Zona da Mata Sul & Manga Espada \\
\hline CM31 & Cabo Sto. Agostinho-PE & Zona da Mata Sul & Manga Comum \\
\hline CM41 & Goiana-PE & Zona da Mata Norte & Rosari \\
\hline CM43 & Goiana-PE & Zona da Mata Norte & Manga Rosa \\
\hline CM44 & Goiana-PE & Zona da Mata Norte & Manga Espada \\
\hline CM45 & Igarassu-PE & Metropolitana Recife & Rosari \\
\hline CM52 & Camaragibe-PE & Metropolitana Recife & Manga Espada \\
\hline CM55 & Lagoa grande-PB & Brejo Paraibano & Manga Espada \\
\hline CM56 & Campus UEMA-MA & Metropolitana São Luís & Manga Rosa \\
\hline CM57 & Dois Irmãos-PE & Metropolitana Recife & Manga Espada \\
\hline CM58 & Campus UFPB-PB & Brejo Paraibano & Manga Espada \\
\hline
\end{tabular}

medindo-se o diâmetro da colônia em intervalos de 24 horas, com auxílio de uma régua milimetrada, tomando-se duas medições, em sentidos diametralmente opostos. Em seguida, foi estabelecida a média de crescimento linear para cada placa. As leituras foram iniciadas 48 horas após a instalação do experimento, até a colonização de toda a superfície do meio de cultura, que correspondeu a sete dias de incubação. Para avaliação do crescimento micelial foram consideradas as leituras feitas até o quinto dia de incubação. O cálculo da taxa de crescimento foi realizado de acordo com Lilly \& Barnett (20).
O delineamento experimental utilizado foi o inteiramente casualizado com quatro repetições, sendo cada repetição constituída por uma placa de Petri. As médias dos dados obtidos foram comparadas utilizando-se o teste de Scott-Knott ao nível de 5\% de probabilidade.

\section{Patogenicidade dos isolados de Colletotrichum}

$\mathrm{Na}$ avaliação do comportamento patogênico, os 40 isolados foram inoculados em folhas jovens, destacadas de mangueira (cultivarEspada), usando-se discos de micélio e meio de cultura $(5 \mathrm{~mm}$ de 
diâmetro) retirados de culturas do patógeno, com cinco dias de idade, crescidas em BDA. A inoculação foi realizada utilizando método com ferimento, produzido com estilete flambado, depositando-se o inóculo em três pontos da superfície foliar. Após a inoculação, as folhas foram acondicionadas em bandejas plásticas forradas com papel de filtro e mantidas em câmara úmida até o aparecimento dos sintomas. Para as testemunhas repetiram-se os mesmos procedimentos, porém sendo depositados somente discos de meio de cultura BDA. As bandejas foram mantidas a $25 \pm 2^{\circ} \mathrm{C}$, sob condição de alternância luminosa (12h claro/ $12 \mathrm{~h}$ escuro).

A avaliação foi realizada aos sete dias após a inoculação, por meio da leitura do diâmetro das lesões e observação das características das lesões.

O delineamento experimental utilizado foi inteiramente casualizado com quatro repetições (representadas por bandejas), e cada parcela constituída por cinco folhas/bandeja, sendo os dados submetidos à análise de variância e as médias comparadas pelo teste de Scott-Knott ao nível de $5 \%$ de probabilidade.

\section{Identificação específica do agente causal da antracnose em mangueira}

Extração e quantificação do DNA fúngico

Os isolados de Colletotrichum foram cultivados em $150 \mathrm{~mL}$ de Batata-dextrose (BD) a temperatura de $252^{\circ} \mathrm{C}$, sob condição de alternância luminosa ( $12 \mathrm{~h}$ claro/ $12 \mathrm{~h}$ escuro), com suaves agitações duas vezes ao dia, durante seis dias. O DNA dos isolados foi extraído a partir de $250 \mathrm{mg}$ de micélio de acordo com o protocolo modificado descrito por Faleiro et al. (10) O micélio foi coletado por filtração e triturado em almofariz com auxílio de nitrogênio liquido. Posteriormente, adicionou-se o tampão de lise (50mM Tris-HCL, $\mathrm{pH}$ 8,0; 50mM EDTA; $\mathrm{NaCl}$ 5M; 3\% dodecil sulfato de sódio (SDS); $1 \%$ de b-mercaptoetanol) seguido de 30 minutos de incubação a $70^{\circ} \mathrm{C} \mathrm{com}$ agitação a cada 10 minutos. Em seguida, as amostras foram centrifugadas a $14.000 \mathrm{rpm}$, durante 10 minutos e aos sobrenadantes foi adicionado clorofórmio-álcool isoamílico (24:1). A seguir as amostras foram agitadas por suaves inversões e novamente centrifugadas. Os sobrenadantes foram transferidos para novos tubos e o processo de desproteinização foi repetido.

Para a precipitação do DNA foram adicionados aos sobrenadantes finais, $\mathrm{NaCl} 5 \mathrm{M}$ e isopropanol refrigerado. Os tubos foram mantidos por 2 horas a $-20^{\circ} \mathrm{C}$, após essa etapa foi repetida a centrifugação. Os precipitados foram lavados duas vezes com etanol $70 \%$ e secos a temperatura ambiente. Posteriormente, os ácidos nucléicos foram ressuspendidos em $150 \mathrm{~mL}$ de água contendo RNAse na concentração de $40 \mathrm{mg} / \mathrm{mL}$ e colocados em banho-maria a $37^{\circ} \mathrm{C}$ por 1 hora para ressuspensão e digestão dos ácidos ribonucléicos. O DNA foi quantificado visualmente em gel de agarose a $0,8 \%$ e corado em solução de brometo de etídio a $0,05 \mathrm{mg} / \mathrm{L}$, a partir da comparação com um padrão de DNA (Low DNA Mass Ladder, Invitrogen).

\section{Análise da seqüência ITS do DNA ribossomal}

Os 40 isolados de Colletotrichum obtidos de mangueira foram submetidos a reação de PCR, com iniciadores específicos ("primer" ITS1). Para C. gloeosporioides foi utilizado o primer (CgInt): 5'GACCCTCCCGGCCTCCCGCC-3' e para C. acutatum o primer (CaInt2): 5'-GGGGAAGCCTCTCGCGG-3' (34). Os oligonucleotídeos foram usados em conjunto com o primer universal conservado ITS4 (5' - TCCTCCGCTTATTGATATTGC-3'), por corresponder a uma seqüência contida na subunidade $28 \mathrm{~S}$ do DNA ribossomal.
A reação de amplificação foi realizada segundo protocolo descrito por Afanador-Kafuri et al. (2), para um volume final de $25 \mathrm{~mL}$ contendo 10 a 70ng de DNA genômico, 0,25mM de cada oligonucleotídeo, $200 \mathrm{mM}$ de dNTPs, $1,5 \mathrm{mM} \mathrm{MgCl}, 1,25 \mathrm{U}$ Taq DNA polymerase e água ultra pura para completar o volume final. A amplificação foi realizada sob as seguintes condições: um ciclo a $95^{\circ} \mathrm{C}$ por 5 minutos, 40 ciclos a $95^{\circ} \mathrm{C}$ por 30 segundos, $65^{\circ} \mathrm{C}$ por 30 segundos e $72^{\circ} \mathrm{C}$ por 1,5 minutos, e um ciclo de $72^{\circ} \mathrm{C}$ por 5 minutos. Os produtos de amplificação foram separados em géis de agarose a 1,5\% em tampão Tris-acetate-EDTA. A eletroforese horizontal ocorreu a $80 \mathrm{~V}$ até que a linha de fronte migrasse $5 \mathrm{~cm}$, em seguida o gel foi corado em solução de brometo de etídio a $0,5 \mathrm{mg} / \mathrm{l}$, tendo os produtos sidos visualizados sobre luz ultravioleta.

\section{RESULTADOS E DISCUSSÃO}

Morfologia e características culturais de Colletotrichum em BDA

Os conídios, oriundos dos isolados, quando observados ao microscópio binocular, apresentaram-se hialinos, unicelulares, cilíndricos ou retos e com ápice obtuso. Estes foram produzidos em acérvulos, na grande maioria dos isolados, em sucessão na extremidade de conidióforos fialídicos ou no ápice de setas e apresentaram grande variação em relação ao comprimento. Resultados semelhantes foram obtidos por Menezes \& Hanlin $(24,25)$ quando estudaram a variabilidade de isolados de C. gloeosporioides obtidos de abacate de diferentes regiões do Nordeste. As dimensões dos conídios estão apresentadas na Tabela 2. Os isolados CM7, CM13, CM15, CM22, CM24, CM38, CM52 e CM55 foram os que apresentaram maiores médias de comprimento, destacando-se o CM52 e CM13, cujos comprimentos $(18,0 \mathrm{~mm})$ foram superiores ao padrão freqüentemente encontrado. Este resultado sugere a ocorrência de segregação genética, a qual pode estar relacionada à condição nuclear dos conídios, fato este já relatado por Serra \& Silva (29) e Menezes \& Hanlin (25). O comprimento médio dos conídios variou de 10,8 a 18,0mm e a largura de 3,2 a 4,3mm. Esta variação, observada em todos os isolados, está dentro dos limites indicados para C. gloeosporioides, segundo Freeman (14). Neste trabalho os isolados apresentaram conídios uninucleados em $90 \%$ dos casos. TeBeest (33), realizando estudos com três espécies de Colletotrichum, observou a presença de conídios uninucleados (97\%), binucleados $(2 \%)$ e trinucleados $(1 \%)$ e segundo o autor o número de núcleos variou com o tipo de meio de cultura usado no estudo.

Embora não seja de valor taxonômico, a presença de setas foi observada em $25 \%$ dos isolados. Estas se apresentaram retas, septadas e escuras, com ápice mais claro. Os isolados que exibiram estas estruturas foram CM1, CM3, CM4, CM5, CM6, CM31, CM39, CM56, CM57 E CM58. Todos os isolados produziram apressórios variados em formato e quantidade, com coloração castanha escura e forma ovalada a irregular, não sendo possível à utilização dessa estrutura para diferenciar os isolados, segundo Menezes \& Hanlin (24). A forma ovalada ou irregular foi a que predominou, sendo possível observar outras formas. Quanto à caracterização quantitativa de formação dos apressórios, os isolados foram agrupados como de produção abundante (...), com produção mediana (..) e com produção escassa (.), conforme mostra a Tabela 2.

As colônias apresentaram grande diversidade com relação à cor e aspecto, de acordo com os diferentes isolados, sendo predominante à cor branco-cinza, característica de C. gloeosporioides (Figura 1). Em alguns casos foi visível a produção de massa de conídios distribuídas em anéis concêntricos na superfície da colônia, de coloração alaranjada 
Tabela 2. Características morfológicas e médias do comprimento e largura dos conídios de 40 isolados de Colletotrichum associados à antracnose em mangueira.

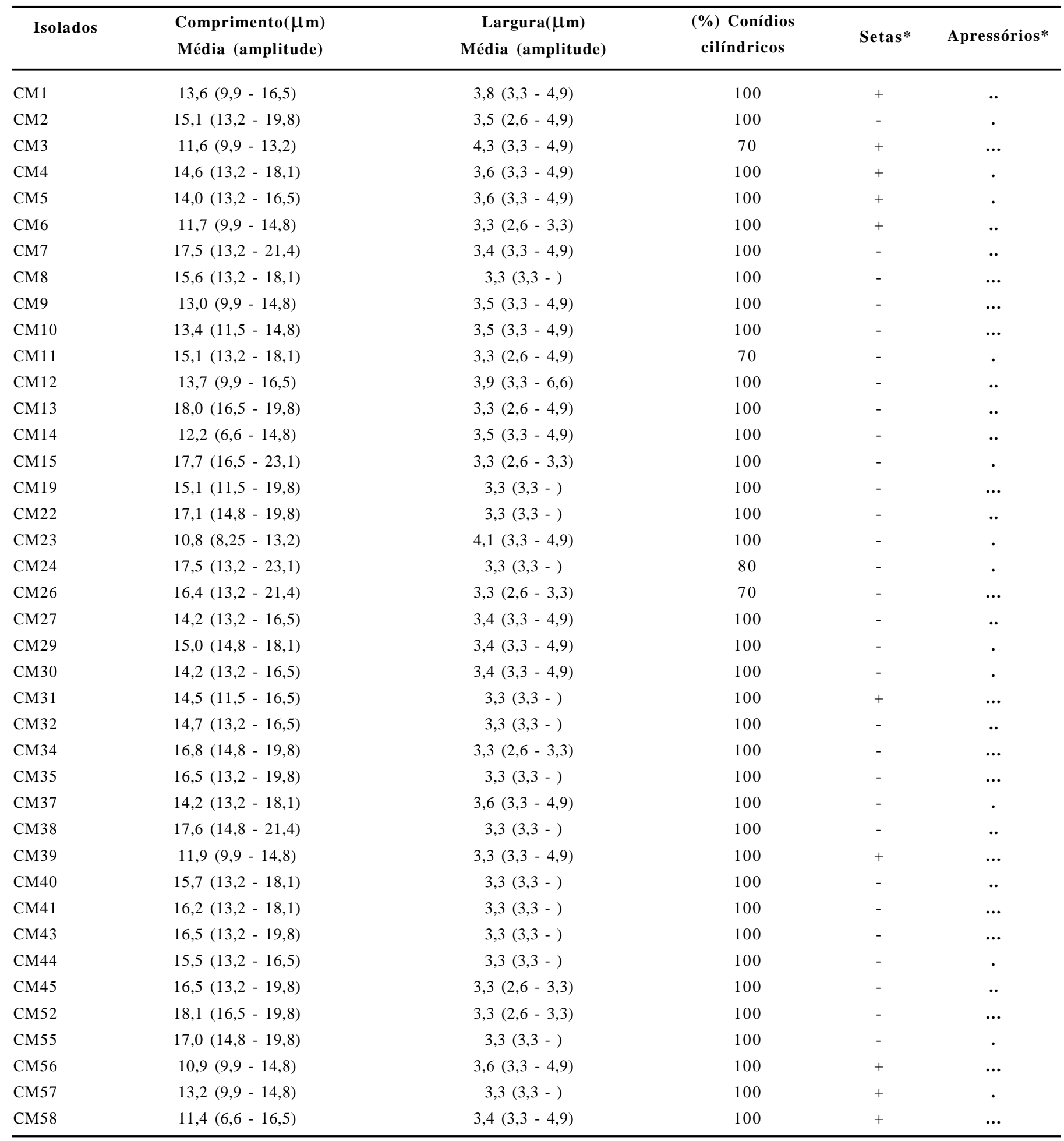

* Indica (+) presença (-) ausência de setas. Produção de apressórios (...) abundante, (..) mediana e (.) escassa.

(CM31- isolado de manga espada). Algumas culturas formaram peritécios, porém com baixa produção de conídios, enquanto que outras produziram conídios em abundância, mas não formaram peritécios. As colônias variaram também quanto à formação de micélio aéreo flocoso sem conídios aparentes, a micélio escasso e submerso, porém bem esporulado, aos sete dias de incubação, destacando-se os isolados CM1, CM3, CM4, CM5, CM10, CM12, CM23, CM31, CM39,
CM56 E CM57 Johnston \& Jones (17), estudando a caracterização cultural, como aspecto de colônias, de diversos isolados de Colletotrichum obtidos de fruteiras, na Nova Zelândia, puderam reconhecer 16 grupos distintos. Estudos semelhantes foram realizados por outros pesquisadores, os quais classificaram isolados de espécies de Colletotrichum em grupos e subgrupos, em função da variação observada em cultura $(1,19)$. 


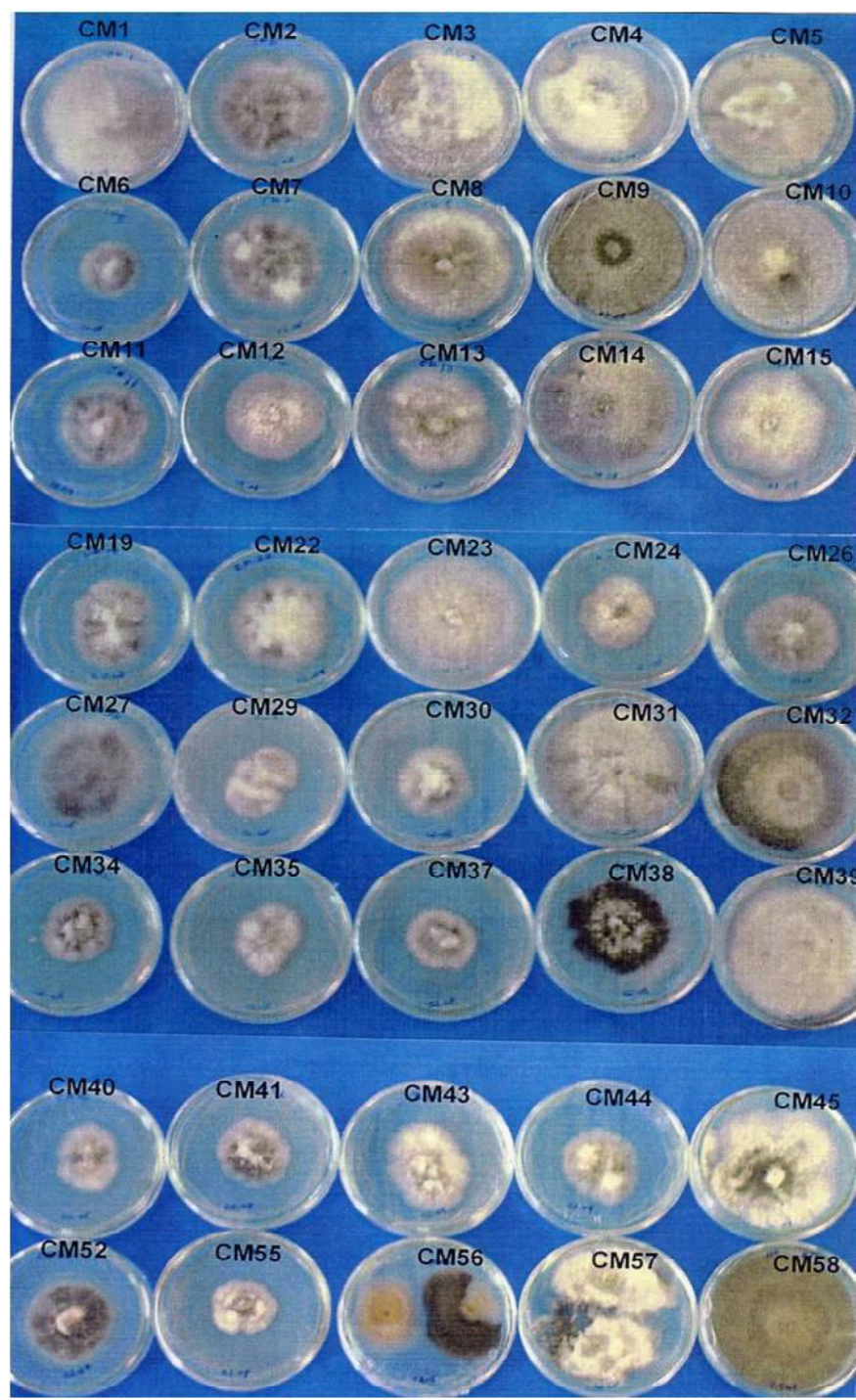

Figura 1. Aspecto cultural das colônias de 40 isolados de Colletotrichum obtidos de mangueira, em meio de Batata-Dextrose-ága (BDA), aos sete dias de incubação.

\section{Caracterização fisiológica e patogênica de Colletotrichum spp obtido de mangueira}

Crescimento micelial em BDA

Os resultados obtidos para o crescimento micelial dos diferentes isolados de Colletotrichum, obtidos de mangueira, estão representados na Tabela 3. O confronto das médias pelo teste Scott-knott, a 5\% de probabilidade, para efeito do crescimento micelial dos isolados, aos cinco dias de incubação, revelou diferenças significativas entre as médias, permitindo a classificação em sete grupos. Os 22 isolados pertencentes aos grupos $1,2,3,4$ e 5 , tiveram crescimento compatíveis com aqueles observados para a espécie de $C$. gloeosporioides. Nos grupos 6 e 7, compreendendo 18 isolados, foram verificados os menores crescimento, destacando-se o isolado CM43, proveniente de Goiana-PE, que apresentou o menor crescimento micelial $(2,69 \mathrm{~cm})$. Estes resultados, conforme Adaskaveg \& Foster (1), podem sugerir o enquadramento dos isolados dos grupos 6 e 7 na espécie $C$. acutatum em função do crescimento reduzido. Entretanto, Freeman et al. (13) relatam que isolados de C. gloeosporioides, obtidos de amendoeira, tem crescimento que não diferem de $C$. acutatum, proveniente de morangueiro. Assim o crescimento micelial não constitui caráter decisivo na determinação de espécies de Colletotrichum, mas pode revelar a ocorrência de variabilidade intraespecífica, visto que a condição heterozigótica ou reprodução sexuada têm possibilidades de gerar novos biótipos na população com comportamento variável.

Quanto à taxa de crescimento micelial, avaliada $\mathrm{em} \mathrm{mm} / \mathrm{dia}$, a análise de agrupamento com base no teste de Scott-Knott possibilitou a classificação dos isolados em sete grupos (Tabela 3). A exemplo do que ocorreu em relação ao crescimento micelial, 22 isolados, pertencentes aos grupos 1, 2, 3 e 4, exibiram taxa de crescimento $>10 \mathrm{~mm} / \mathrm{dia}$, considerada como típica da espécie $C$. gloeosporioides, segundo Adaskaveg \& Foster (1). Os isolados CM12 e CM38, do grupo 4, e os demais isolados dos grupos 5, 6 e 7, tiveram crescimento inferior a $10 \mathrm{~mm}$, exibindo, portanto, características de C. acutatum. O CM43 apresentou a menor taxa de crescimento $(1,44 \mathrm{~mm} / \mathrm{dia})$, constituindo o único representante no grupo 7. Do mesmo modo que no crescimento micelial, a taxa de crescimento não deve ser considerada caráter de valor taxonômico essencial, podendo, no entanto, caracterizar variabilidade intraespecífica em Colletotrichum spp.

\section{Patogenicidade dos isolados de Colletotrichum}

Todos os isolados foram patogênicos em folhas destacadas de mangueira, induzindo sintomas de antracnose na forma de manchas escuras levemente deprimidas. A avaliação da patogenicidade dos isolados, por meio do diâmetro das lesões, apresentou diferenças estatísticas significativas entre isolados (Tabela 3). Com base no teste de Scott-Knott foi possível separar os isolados em cinco grupos de acordo com a agressividade. Os grupos 1 e 2 foram os mais agressivos, no entanto, compreenderam apenas 6 isolados, conforme mostra a Figura 2. O grupo 5, contendo 15 isolados, foi o menos agressivo. O isolado CM31 apresentou o menor diâmetro de lesão, sendo considerado o menos agressivo.

A variabilidade patogênica é um parâmetro de grande importância na caracterização de isolados de Colletotrichum e, em função disto, diversos trabalhos têm sido desenvolvidos levando em consideração esta característica $(2,16)$. Souza \& Sobrinho $(30)$, estudando isolados de C. gloeosporioides obtidos de mangueira, quanto às características morfológicas e patogênicas, evidenciaram variabilidade entre os isolados. Avaliando a patogenicidade de 290 isolados de $C$. gloeosporioides, provenientes de abacateiro e mangueira, Swart (31) mostrou que houve formação de grupos baseado na agressividade dos isolados. Os obtidos de mangueira formaram três grupos, comparado com os de abacateiro que formaram quatro grupos, sendo comprovada variação na agressividade dos isolados.

Exceto pelos isolados mais agressivos, coletados em Goiana-PE (CM40, CM41 e CM43) e Cabo de Santo Agostinho-PE (CM29 e CM35), não foi possível estabelecer uma relação entre a origem geográfica e agressividade dos isolados. Resultados semelhantes foram obtidos por Assunção (4) ao não detectar agressividades diferenciadas em isolados de C. gloeosporioides, obtidos de cebola, com relação às suas origens.

A análise de Correlação de Pearson para as variáveis, crescimento micelial, taxa de crescimento e diâmetro da lesão (Tabela 3 ) evidenciou correlação positiva $(0,9357)$ significativa ao nível de $1 \%$ de probabilidade, entre crescimento e taxa de crescimento e correlação negativa entre crescimento micelial e diâmetro da lesão $(-0,5390)$ e taxa de crescimento e diâmetro da lesão $(-0,5989)$. Na primeira correlação, de classificação de 
Tabela 3 - Crescimento micelial aos cinco dias de incubação, taxa de crescimento micelial e patogenicidade dos 40 isolados de Colletotrichum obtidos de mangueira.

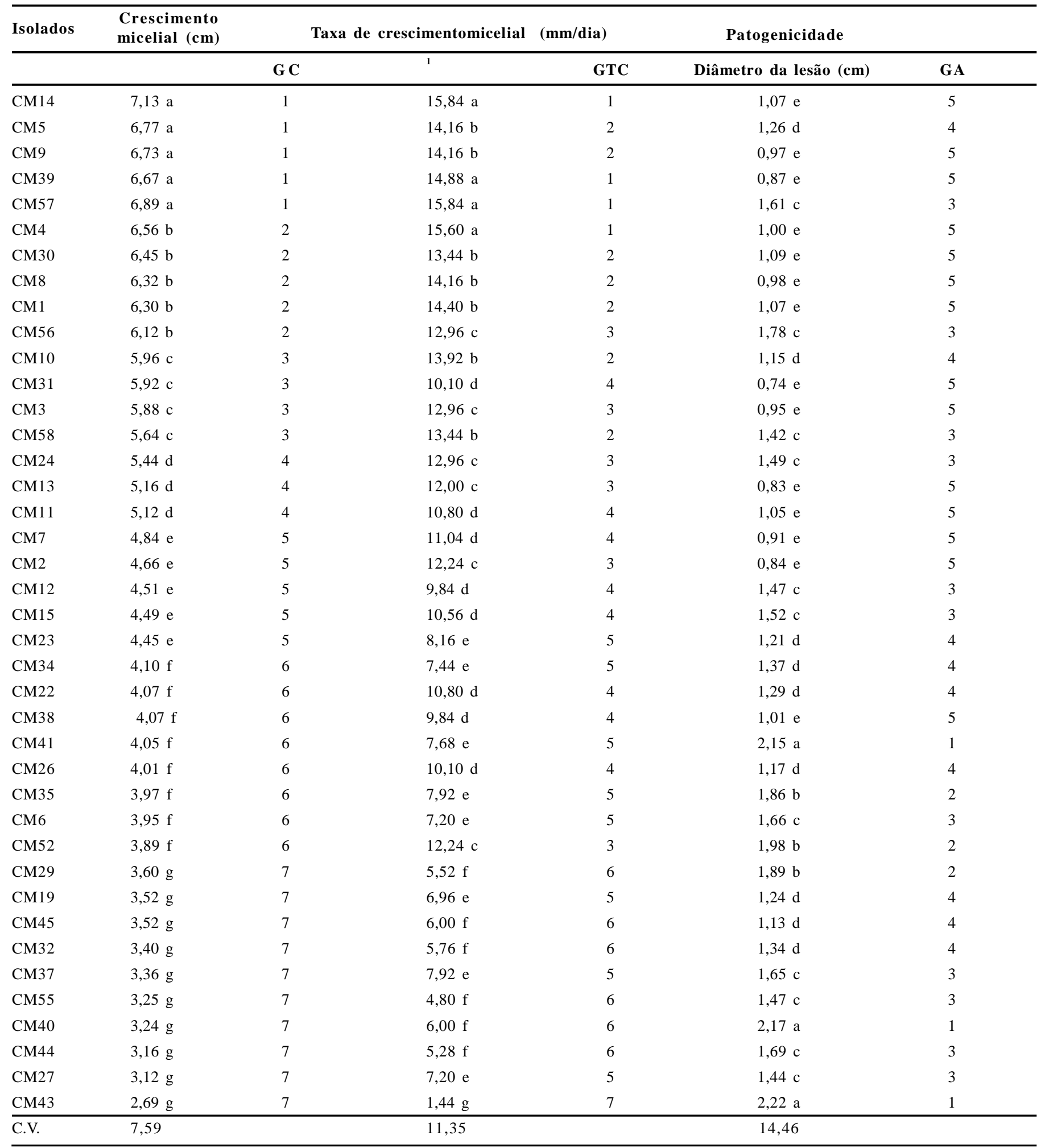

* Txc $=($ C96-C48)/T (Lilly \& Barnet, 1951). Média de quatro repetições. Médias seguidas pela mesma letra minúscula (no sentido vertical), pertencem ao mesmo grupo, de acordo com o teste de Scott-Knot ao nível de $5 \%$ de probabilidade.

${ }^{1}$ GC - grupo de crescimento micelial; GTC - grupo de taxa de crescimento; GA - grupo de agressividade. 
magnitude muito alta (26), confirmou-se o resultado esperado, visto que a taxa de crescimento é calculada em função do crescimento dos isolados. Entretanto, nas demais correlações, verificaram-se, em nível de classificação substancial, que quanto menor o crescimento ou taxa de crescimento, maior a agressividade do isolado. Isto pode ser destacado em relação aos isolados CM40, CM41 e CM43 que exibiram baixas taxas de crescimento e maiores diâmetros de lesões. Este resultado sugere a possibilidade do uso do crescimento micelial em BDA para classificação e seleção de isolados mais agressivos de Colletotrichum em mangueira, devendose, porém, ser exigida correlação de maior magnitude que a observada. Em alguns fungos fitopatogênicos, correlações variáveis têm sido relatadas entre o crescimento micelial e agressividades, sendo não significativas como nos patossistemas $C$. gloeosporioides - mangueira (3) e Fusarium udum Butler - guandu (Cajanus cajan (L.) Millsp.) (18) e significativas observadas nos patossistemas Phytophthora cinnamomi Rands -Eucalyptus smithii R.T. Baker $(\mathrm{r}=0,51)$, segundo Linde et al. (21) e Microdochium nivale (Fr.) Samuels \& Hallet (= Fusarium nivale $)$ - trigo $(\mathrm{r}=-0,80)(6)$.

\section{Análise da seqüência ITS do DNA ribossomal}

O DNA de 40 isolados de Colletorichum spp. obtidos de mangueira foi amplificado com os oligonucleotídeos específicos para C. gloeosporioides (CgInt) e C. acutatum (CaInt2), conforme mostra a Tabela 4. Os produtos de PCR dos isolados representativos da população estão apresentados na Figura 3. Todos os isolados amplificaram com os oligonucleotídeos CgInt e o ITS4, com exceção dos isolados CM1, CM4, CM5 e CM10, que não amplificaram produtos para nenhum dos oligonucleotídeos específicos, sendo identificados como Colletotrichum spp., apesar de terem sido caracterizados como C. gloeosporioides, com base nas características morfológicas. Resultados semelhantes foram encontrados por Afanador-Kafuri et al. (2) que observaram incongruência entre critérios morfológicos e moleculares para identificação de espécies de Colletotrichum de tamarineira, mangueira e maracujazeiro.

Os oligonucleotídeos específicos para C. gloeosporioides e $C$. acutatum tem sido bastante usados em vários estudos para identificação de populações de Colletotrichum que causam antracnose em vários hospedeiros. Por exemplo, Forster \& Adaskaveg (12) usando os mesmos oligonucleotídeos, confirmou que $C$. acutatum é a espécie causal de antracnose em amendoeira na Califórnia. Brown et al. (7) confirmaram que C. gloeosporioides e C. acutatum são responsáveis por antracnose em Citrus na Florida. Estudos realizados por Afanador-Kafuri et al. (2) demonstraram que os oligonucleotídeos CaInt2 e CgInt foram eficientes para diferenciar isolados de Colletotrichum obtidos de tamarineira e mangueira a nível de espécie. Baseado na análise da região ITS- rDNA, com os oligonucleotídeos específicos, os autores puderam confirmar que todos os isolados de tamarineira, foram identificados como $C$. acutatum e que os obtidos de mangueira, foram identificados como $C$. gloeosporioides.

Estudos com antracnose em mangueira demonstraram que o desenvolvimento de estratégias de controle eficientes e rentáveis tem sido facilitado devido a uma determinação precisa da etiologia de doenças causadas por Colletotrichum e um melhor conhecimento da

Tabela 4 - Identificação espécie-específica de isolados de Colletotrichum obtidos de mangueira a partir da amplificação da região ITS do rDNA, usando os primers CaInt2/ITS4 e CgInt/ITS4 ${ }^{\mathrm{a}}$.

\begin{tabular}{|c|c|c|c|c|c|c|c|}
\hline Isolado & \multicolumn{2}{|c|}{ Reação dos primers } & Espécies & Isolado & \multicolumn{2}{|c|}{ Reação dos primers } & Espécies \\
\hline CM1 & - & - & Colletotrichum sp. & $\mathrm{CM} 27$ & + & - & C. gloeosporioides \\
\hline CM3 & + & - & C. gloeosporioides & CM30 & + & - & C. gloeosporioides \\
\hline $\mathrm{CM} 4$ & - & - & Colletotrichum sp. & CM31 & + & - & C. gloeosporioides \\
\hline CM7 & + & - & C. gloeosporioides & CM35 & + & - & C. gloeosporioides \\
\hline CM8 & + & - & C. gloeosporioides & CM37 & + & - & C. gloeosporioides \\
\hline CM9 & + & - & C. gloeosporioides & CM38 & + & - & C. gloeosporioides \\
\hline CM10 & - & - & Colletotrichum sp. & CM39 & + & - & C. gloeosporioides \\
\hline CM11 & + & - & C. gloeosporioides & $\mathrm{CM} 40$ & + & - & C. gloeosporioides \\
\hline CM15 & + & - & C. gloeosporioides & CM45 & + & - & C. gloeosporioides \\
\hline CM19 & + & - & C. gloeosporioides & CM52 & + & - & C. gloeosporioides \\
\hline CM22 & + & - & C. gloeosporioides & CM55 & + & - & C. gloeosporioides \\
\hline CM23 & + & - & C. gloeosporioides & CM56 & + & - & C. gloeosporioides \\
\hline $\mathrm{CM} 24$ & + & - & C. gloeosporioides & CM57 & + & - & C. gloeosporioides \\
\hline CM26 & + & - & C. gloeosporioides & CM58 & + & - & C. gloeosporioides \\
\hline
\end{tabular}

arimer CgInt (C. gloeosporioides) e CaInt2 (C. acutatum) foram usados conjuntamente com o primer ITS4 para amplificação da região ITS e identificação das espécies de Colletotrichum. A amplificação do DNA fúngico de cada isolado foi designada (+) positiva ou (-) negativa. 


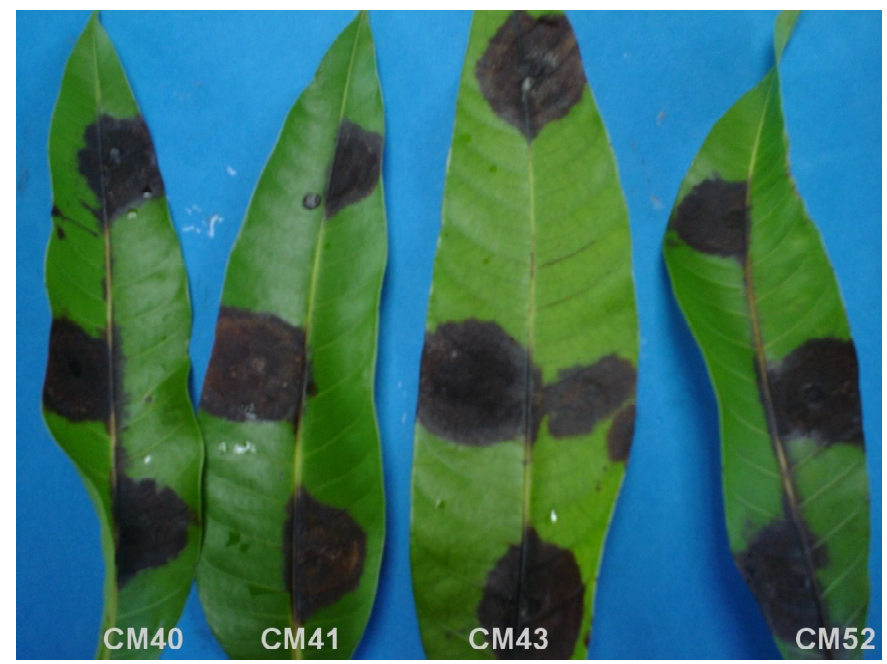

Figura 2. Patogenicidade dos isolados de Colletotrichum CM40, CM41, CM43 e CM52, pertencentes aos grupos de agressividade 1 e 2, mostrando manchas escuras e levemente deprimidas.

interação patógeno-hospedeiro, que determina o sucesso na patogênese $(2,11,31,34)$. Nesse sentido os resultados obtidos no presente trabalho forneceram subsídios para o conhecimento da etiologia da antracnose em mangueira no Nordeste brasileiro.

\section{AGRADECIMENTOS}

Os autores agradecem a Profa. Luíza Suely Sêmen Martins pela disponibilização da infra-estrutura do Laboratório do Genoma da Universidade Federal Rural de Pernambuco para realização das análises moleculares.

\section{REFERÊNCIAS BIBLIOGRÁFICAS}

1. Adaskaveg, J.E.; Forster, H. Occurrence and management of anthracnose epidemics caused by Colletotrichum species on tree fruit crops in California. In: Prusky, D.; Freeman, S.; Dickman, M.B. (Ed.). Colletotrichum: host specificity, pathology and hostpathogen interaction. St. Paul: APS Press, 2000. cap.6, p.317336.
2. Afanador-Kafuri, L; Minz, D.; Maymon, M.; Freeman, S. Characterization of Colletotrichum isolates from tamarillo, passiflora, and mango in Colombia and identification of a unique species from the genus. Phytopathology, St. Paul, v.93, p.579-587, 2003 .

3. Assis, T. C. Variabilidade de Colletotrichum gloeosporioides, agente causal da antracnose da mangueira, quanto utilização de carboidratos, patogenicidade, produção de enzimas e analise RAPD. 2001. 138p. Dissertação (Mestrado em Fitossanidade) - Universidade Federal Rural de Pernambuco, Recife.

4. Assunção, I.P. Identificação de fontes de resistência em cultivares de cebola (Allium cepa $\mathbf{L}$.) e análise da variabilidade de Colletotrichum gloeosporioides (Penz.) Penz. \& Sacc. (Sensu arx, 1957) assistida por marcadores moleculares. 1997. 120p. Dissertação (Mestrado em Fitossanidade) - Universidade Federal Rural de Pernambuco, Recife.

5. Balardin, R.S.; Pastor-Corrales, M.A. Reação de germoplasma de Phaseolus vulgaris a nove raças de Colletotrichum lindemuthianum. Fitopatologia Brasileira, Fortaleza, v.15, p.269-273, 1990.

6. Brennan, J.M.; Fagan, B.; Van Maanem, A.; Cooke, B.M.; Doohan, F.M. Studies on in vitro growth and pathogenicity of European Fusarium fungi. European Journal of Plant Pathology, Wageningen, v.109, p.577-587, 2003.

7. Brown, A.; Sreenivasaprasad, S.; Timmer, L.W. Molecular characterization of slow-growing orange and Key lime anthracnose strains of Colletotrichum from citrus as C. acutatum. Phytopathology, St. Paul, v.86, p.523-527, 1996.

8. Costa, R.V.; Casela, C.R.; Zambolim, L.; Ferreira, A.S. A antracnose do sorgo. Fitopatologia Brasileira, Brasília, v.28, p.345$354,2003$.

9. Cunha, M. M.; Coutinho, C. C.; Junqueira, N. T. V.; Ferreira, F. R. Manga para exportação: aspectos fitossanitários. Brasília: EMBRAPA, 1993.104p. (FRUPEX, 3).

10. Faleiro, F.G.; Luz, E.D.M.N. Cerqueira, A.O.; Rocha, C.S.S.; Dantas Neto, A.; Flores, A.B.; Bahia, R.C.S.; Faleiro, A.S.G. Caracterização e diversidade genética de isolados de Phytophthora spp. do cacaueiro com base em marcadores RAPD. Fitopatologia Brasileira, Brasília, v.29, p.303-306, 2004.

11. Fitzell, R.D.; Peak, C.M. The epidemiology of anthracnose disease of mango -Inoculum sources, spore production and dispersal. Annals of Aplplied Biology, St. Paul, v.104, p.53-59, 1984.

12. Forster, H.; Adaskaveg, J.E. Identification of subpopulations of Colletotrichum acutatum and epidemiology of almond anthracnose in California. Phytopathology, St. Paul, v.89, p.10561065,1999

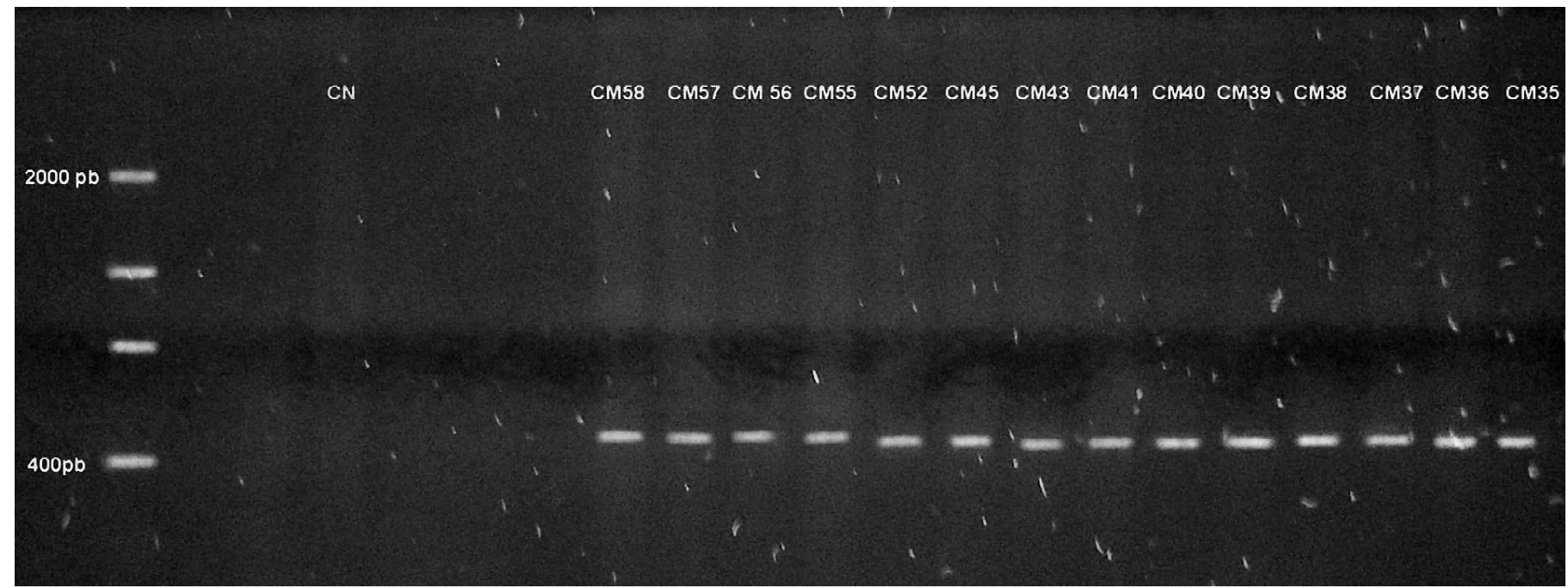

Figura 3. Amplificação da região ITS e identificação específica de isolados de Colletotrichum, obtidos de mangueira, usando o primer CgInt (Colletotrichum gloeosporioides) em combinação com ITS4. 
13. Freeman, S.; Katan, T.; Shabi, E. Characterization of Colletotrichum species responsible for anthracnose diseases of various fruits. Plant Disease, St. Paul, v.82, p.596-605, 1998.

14. Freeman, S. Genetic diversity and host specificity of Colletotrichum species on various fruits. In: Prusky, D.; Freeman, S.; Dickman, M.B. (Ed.). Colletotrichum: host specificity, pathology and host-pathogen interaction. St. Paul: APS Press, 2000. p.131143.

15. Freeman, S.; Minz, D.; Maymon, M.; Zveibil, A. Genetic diversity within Colletotrichum acutatum sensu Simmonds. Phytopathology, St. Paul. v.91, p.586-592, 2001.

16. Freeman, S.; Shalev, Z.; Katan, T. Survival in soil of Colletotrichum acutatum and C. gloeosporioides pathogenic on strawberry. Plant Disease, St. Paul, v.66, p.965-970, 2002.

17. Johnston, P.R.; Jones, D. Relationships among Colletotrichum isolates from fruit-rots assessed using rDNA sequences. Mycological, Cambridge, v.89, p.420-430, 1997.

18. Kiprop, E.K.; Mwang'Ombe, A.W.; Baudoin, J.P.; Kimani, P.M.; Mergeai, G. Cultural characteristic, pathogenicity and vegetative compatibility of Fusarium udum isolates from pigeonpea (Cajanus cajan (L.) Millsp.) in Kenya. European Journal of Plant Pathology, Wageningen, v.108, p.147-154, 2002.

19. Latinovié, J.; Vueinié, Z. Cultural characteristics, pathogenicity, and host range de Colletotrichum gloeosporioides isolated from olive plants in Montenegro. Acta Hortciense, Leuven, v.586, p.753-755, 2002 .

20. Lilly, V.G.; Barnett, H.L. Physiology of the fungi. New York: McGraw-Hill. 1951. 464p.

21. Linde, C.; Kemp, G.H.J.; Wingfield, M.J.; Variation in pathogenicity among South African isolates of Phytophthora cinnamomi. European Journal of Plant Pathology, Wageningen, v.105, p.231-239, 1999.

22. Menezes, M. Aspectos biológicos e taxonômicos de espécies do gênero Colletotrichum. Fitopatologia Brasileira, Brasília, v.27, p.523-524, 2002 (suplemento).

23. Menezes, M.; Assis, S.M.P. Guia pratico para fungos fitopato-

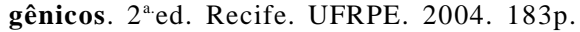

24. Menezes, M.; Hanlin, R.T. Apressoria of brazilian isolates of Colletotrichum gloeosporioides (Penz.) Sacc. causal agent of anthracnoses diseases. Revista de Microbiologia, São Paulo, v.27, p.247-251, 1996a.

25. Menezes, M.; Hanlin, R.T. Morphological variability of Colletotrichum gloeosporioides isolates from avocado trees from Northeastern Brazil. Revista de Microbiologia, São Paulo, v.27, p.228-236, 1996 b.

26. Miller, L.E. Correlations: description or inference? Journal of Agricultural Education, St. Paul, v.35, p.5-7, 1994.

27. Ribeiro, I.J.A. Doenças da mangueira. In: Kimati, H. et al. (Ed.) Manual de fitopatologia: doenças de plantas cultivadas. 4. ed. São Paulo: Editora Ceres, 2005. p.457-465.

28. Screenivasaprasad, S.; Talhinhas, P. Genotypic and phenotypic diversity in Colletotrichum acutatum, a cosmopolitan pathogen causing anthracnose on a wide range of hosts. Molecular Plant Pathology, Bristol, v.6, p.361-378, 2005.

29. Serra, I.M.R.S.; Silva, G.S. Caracterização morfofisiológica de isolados de Colletotrichum gloeosporioides agentes de antracnose em frutíferas no Maranhão. Summa Phytopathologica, Jaboticabal, v.30, p.475-480, 2004.

30. Souza, C. L. C.; Almeida Sobrinho, C. Avaliação da variabilidade morfológica e patogênica do agente causal da antracnose na mangueira. Fitopatologia Brasileira, Brasília, v.33, p.426, 2000. (Resumo).

31. Swart, G.M. Comparative study of Colletotrichum gloeosporioides from avocado and mango. 1999, 156p. Thesis (PhD) Faculty of Biological and Agriculture Sciences/ University Pretoria. Pretoria, 1999.

32. Talhinhas, P.; Screennivasaprasad, S.; Neves-Martins, J.; Oliveira, H. Molecular and phenotypic analyses reveal the association of diverse Colletotrichum acutatum groups and a low level of $C$ gloeosporioides with olive anthracnose. Applied Environmental Microbiology, St. Paul, v.71, p.2987-2998, 2005.

33. Tebeest, D. O. Survival of Colletotrichum gloeosporioides f. sp. aeschynomene in rice irrigation water and soil. Plant Disease St. Paul, v.66, p.469-471, 1982.

34. Xiao, C.L.; Mackenzie, S.J.; Legard, D.E. Genetic and pathogenic analyses of Colletotrichum gloeosporioides isolates from strawberry and noncultivated hosts. Phytopathology, St. Paul, v.94, p.446-453, 2004. 